\title{
Fenòmens de contacte lingüístic en el lèxic disponible català de Lleida
}

\section{Language contact phenomena in the lexicon available in Lleida's Catalan language}

\author{
Maribel Serrano Zapata \\ Departament de Filologia Clàssica, Francesa i Hispànica, Universitat de Lleida, \\ Plaça Víctor Siurana, 1, 25001 Lleida \\ e-mail: mserrano@filcef.udl.cat
}

\begin{abstract}
This article aims to analyse the influence of Spanish on the lexicon available in Catalan. For this purpose, we examine to what extent the Catalan lexicon contains elements of Spanish and what value these units have within the data available. We have also classified language contact phenomena and we have specifically analysed the instances of loans in our corpus. In order to carry out this research, we have mainly focused on the data from the province of Lleida, obtained from 240 pre-college informants who filled out an associative survey regarding 17 centers of interest.
\end{abstract}

Keywords: language contact, linguistic transfers, lexical availability, bilingualism

\section{INTRODUCCIÓ}

La disponibilitat lèxica és una línia d'investigació que actualment té un desenvolupament notable en la lingüística hispànica. Els treballs duts a terme sobre la llengua catalana, per contra, són molt més escassos ${ }^{1}$. Aquesta disciplina s'emmarca dins de la lexicoestadística i, per tant, tracta d'atorgar índexs estadístics a les diferents unitats d'una llengua. Amb la disponibilitat lèxica, concretament, s'intenta establir quines paraules estan a disposició del parlant davant d'un tema concret o situació determinada ${ }^{2}$. La metodologia que s'utilitza

\footnotetext{
${ }^{1}$ Les úniques excepcions en són l'estudi de Gómez Devís (1995) i el de Llopis (2009), circumscrits a la província de València, i les nostres pròpies dades (Serrano Zapata, 2014).

${ }^{2}$ Els esforços realitzats amb aquesta mateixa finalitat que consideraven únicament el criteri de freqüència en el discurs van resultar del tot infructuosos, ja que donaven com a resultat llistats integrats sobretot per preposicions, conjuncions i articles, és a dir, paraules gramaticals que de ben poc serveixen a l'hora de comunicar-se.
} 
és ben senzilla: s'ofereix un estímul verbal, com per exemple, "El cos humà", i amb un temps limitat de dos minuts un informant ha d'anomenar tots aquells mots que se li acudeixin. Aquesta mateixa operació es repeteix amb altres estímuls, tots ells propers a la vida quotidiana dels individus. D'aquesta forma, es recullen els termes que hom té més a l'abast, però que només s'activen en alguns contextos concrets i que, d'altra forma, no apareixerien fàcilment en un discurs pres a l'atzar.

Les dades que utilitzem en aquest treball provenen de les respostes aportades per 240 informants preuniversitaris de dotze centres d'educació secundària de diferents punts de la província de Lleida ${ }^{3}$. Aquests estudiants van omplir una enquesta associativa sobre un total de disset centres d'interès, i les respostes, després d'un procés d'edició i homogeneïtzació, van ser introduïdes al banc de dades de la pàgina www.dispolex.com per fer-ne la quantificació matemàtica ${ }^{4}$. El fruit final d'aquest procés és el diccionari de lèxic disponible, on totes les paraules s'ordenen d'acord amb l'índex de disponibilitat i on s'ofereix, a més, la freqüència relativa, el percentatge d'aparició i la freqüència acumulada de cada mot ${ }^{5}$.

Els resultats que ofereixen els estudis de disponibilitat lèxica poden analitzar-se des de diferents disciplines; tanmateix, l'enfocament que seguim en aquestes pàgines és el sociolingüístic, i utilitzem els llistats que proporcionen aquests tipus d'estudis per determinar quina és la influència que té el castellà sobre la llengua pròpia del territori. La metodologia del nostre treball permet no només esbrinar quina quantitat del lèxic català -que hom té a l'abast en anomenar un estímul concret- pertany, de fet, al castellà -és a dir, quina part d'aquest lèxic 'mental' són termes en realitat castellans-, sinó que, a més a més, permet conèixer quin grau d'integració o de difusió social tenen aquestes unitats -quants

${ }^{3}$ Concretament, sis d'aquests centres són a la ciutat de Lleida i els altres sis es troben a les poblacions següents: La Seu d'Urgell, Tàrrega, Almacelles, Les Borges Blanques, Solsona i Vielha. Les enquestes es van passar durant el curs 2002-2003 i els informants suposaven el 9,71\% del total d'alumnes matriculats a segon de batxillerat aquell any. Dels 240 estudiants, el 65,42\% (157) tenia el català com a llengua materna i el 27,50\% (66), el castellà. El 7,08\% (17) restant va afirmar tenir l'aranès o les dues llengües oficials de la comunitat (català/castellà) com a maternes.

${ }^{4}$ Per a més informació sobre la metodologia, vg. Serrano Zapata (2014, pp. 225-311). De fet, els resultats que presentem aquí formen part d'una investigació més àmplia que estableix i analitza el lèxic disponible en castellà $i$ català a la província de Lleida.

${ }^{5}$ L'índex de disponibilitat es calcula en funció de dos paràmetres: el nombre d'aparicions d'un terme i la seva posició als llistats, afavorint així els vocables que apareixen en primer lloc i que, per tant, són més "disponibles" a la ment de l'informant. La freqüència relativa és el nombre de vegades que apareix un mot respecte al total, el percentatge d'aparició, el nombre d'informants que han inclòs aquella paraula, i la freqüència acumulada és la suma de les freqüències relatives. Els diccionaris complets del lèxic disponible català de Lleida es poden consultar a Serrano Zapata (2014, pp. 865-1108). 
informants les esmenten o si aquestes substitueixen o no el vocabulari propi de la llengua catalana- ${ }^{6}$. Partim de la hipòtesi que, donada la situació actual de contacte lingüístic entre el castellà i el català que hi ha a la província de Lleida, és més que probable que trobem elements lingüístics del castellà en el lèxic disponible català.

\section{CLASSIFICACIÓ DELS FENÒMENS DE CONTACTE LINGÜÍSTIC}

Seguidament, presentem els fenòmens de contacte de llengües que hem trobat en el lèxic disponible català. Per tal de classificar-los, hem utilitzat alguns dels criteris establerts en la literatura clàssica, com la freqüència d'ús o el desplaçament de sinònims (Gimeno \& Gimeno, 2003, p. 110). Per tal de diferenciar entre els diferents fenòmens, ens hem basat en el grau d'integració social, mesurat a través del nombre de mencions de cada unitat ${ }^{7}, i$ en la noció de gramaticalitat/agramaticalitat.

El fet que no hi hagi una terminologia unànime per a aquest tipus d'elements obliga a redefinir en cada treball els termes que s'utilitzen per a cada fenomen en concret, tal com fem a continuació ${ }^{8}$. Per anomenar globalment tots aquests elements utilitzem en aquest treball de forma sinònima els termes fenòmens de contacte lingüistic i transferències.

a. Interferències: anomenem així tots aquells elements que són agramaticals i propis de l'idiolecte, és a dir, que manquen d'integració social, tal com es dedueix del baix percentatge d'informants que els inclouen. En concret, hem considerat d'aquesta forma els termes agramaticals ${ }^{9}$ amb un percentatge d'aparició inferior al 5\%.

\footnotetext{
${ }^{6}$ No obstant això, la metodologia de la disponibilitat lèxica compta amb algunes limitacions, com per exemple que l'aparició de transferències ve condicionada pels temes que s'ofereixen a l'informant. Una altra dificultat específica amb què ens hem trobat ha estat la de distingir quins elements es consideraven d'una llengua i quins de l'altra; no és tan fàcil -com pot semblar a prio$r i-$ establir aquesta distinció (vg. Serrano Zapata, 2014, pp. 493-498).

${ }^{7}$ Aquesta informació l'hem extreta del percentatge d'aparició de cada paraula, que apareix a la tercera columna dels diccionaris finals, i que indica quants informants, sobre cent, han inclòs aquest terme. D'altra banda, no tenim en compte l'índex de disponibilitat perquè l'ordre de les paraules està condicionat per la relació que tenen amb l'estímul determinat que s'ofereix a l'informant.

${ }^{8}$ Vegeu la similitud de la nostra classificació amb la de Llopis (2009), a qui, en part, seguim.

${ }^{9}$ Tot $\mathrm{i}$ reconèixer que el concepte seria més ampli, considerem en aquest treball com agramaticals els mots que no apareixen en el diccionari normatiu ni en altres diccionaris de referència de la llengua catalana. Tots aquests vocables es troben marcats en les pàgines següents amb un asterisc. Malgrat això, algunes d'aquestes veus, com per exemple avespa*, garaig* o llimpiar*, estan recollides en alguns dels diccionaris dialectals del català de la zona, com el de Massana (2004) o el
} 
b. Préstecs en procés d'integració: són aquelles paraules que apareixen quan el parlant desconeix el terme adequat en català. La seva aparició a les dades ve determinada per un nivell relatiu d'integració social, que indica que un nombre considerable de les persones enquestades actualitzen el terme en qüestió, la qual cosa podria indicar que és un fenomen en moviment en la comunitat de parla. Aquestes veus arriben a un percentatge d'aparició d'entre el 5 i el 15\%.

c. Préstecs integrats: a diferència del concepte anterior, aquest tipus de préstecs ja té un grau notable d'integració social, determinat tant pel desplaçament del sinònim corresponent de la llengua base com per l'alta freqüència de mencions. En aquest cas, els préstecs es poden estendre també als parlants monolingües de la mateixa comunitat i els enquestats no són conscients que fan servir una paraula d'una altra llengua. Aquest tipus de préstecs tenen un percentatge d'aparició superior al $15 \%$ en el nostre corpus.

d. Canvis de codi: es diferencien de les interferències en el fet que els canvis de codi són termes gramaticals i normatius, però que no s'ajusten a la llengua de l'enquesta. El percentatge de parlants que les mencionen és baix, fet que demostra que no compten amb integració social. Igual que les interferències, el percentatge d'aparició és inferior al 5\%.

e. Combinacions híbrides: sota aquesta etiqueta agrupem els casos que suposen una amalgama entre les dues llengües, en el sentit que, generalment en una combinació sintagmàtica, apareix un terme en una llengua i un altre en una altra, la qual cosa fa molt difícil determinar a quina llengua correspon la unitat en conjunt. Dins d'aquesta categoria podem distingir entre els següents tipus de combinacions sintagmàtiques: (i) amb el nucli en castellà, (ii) amb el nucli en català, (iii) formades per dos lexemes dels quals, normalment, un pertany al castellà i l'altre al català, i (iv) les que es formen a partir d'algun element híbrid ${ }^{10}$.

f. Calc sintàctic: aquest nom correspon a una unitat lèxica amb més d'un element, però en aquest cas el que es transfereix des de l'altra llengua és l'esquema de la combinació dels diversos elements del sintagma, tots ells pertanyents a la llengua catalana ${ }^{11}$.

de Masip, Montardit \& Prenafeta (2010). Sobre les limitacions que presenten aquests diccionaris, pot consultar-se Serrano Zapata (2014, p. 218).

${ }^{10}$ Poden servir els següents exemples: (i) "pantalón curt", (ii) "tallar el césped", (iii) lavavaixelles* o secaplats*, i (iv) armari roper* o ingenier* agrònom. Alguns dels exemples del darrer cas són, a més, préstecs que compten amb una integració social considerable, com veurem en el darrer apartat.

${ }^{11}$ Alguns exemples són pati de llum ("patio de luces", celobert) o ou fregit ("huevo frito", ou ferrat). 
g. Calc semàntic: tampoc en aquesta ocasió es transfereix un element d'un altre idioma, sinó que una paraula pren un nou significat per contacte amb un vocable de l'altra llengua amb el qual presenta una similitud formal i semàntica. Com que les dues llengües estan relacionades genèticament, tots els casos del nostre corpus que s'agrupen sota aquesta etiqueta comparteixen, a més, un mateix ètim, normalment llatí ${ }^{12}$.

La nostra classificació té algunes limitacions. La principal deriva del fet que combinem un criteri formal amb un altre on tenim en compte la integració social del terme. Per aquest motiu, algunes combinacions hibrides, calcs sintàctics o semàntics poden ser també exemples de préstecs $^{13}$.

\section{ANÀLISI QUANTITATIVA}

A continuació estudiem el pes quantitatiu que tenen els fenòmens de contacte lingüístic sobre el conjunt de les dades. En primer lloc, en el següent gràfic podem observar la distribució de les transferències segons la classificació que hem realitzat.

El fenomen que més es dóna als nostres llistats és la presència d'un terme gramatical i normatiu en castellà, l'aparició del qual s'explica -en la nostra opinió- per un oblit momentani del mot adequat en la llengua en què s'està completant l'enquesta, és a dir, el català. Després dels canvis de codi, el segon tipus de transferència més freqüent és la interferència, cosa que ens porta a concloure que entre els fenòmens de contacte trobats predominen les produccions individuals esporàdiques, ja siguin dins o fora de la norma.

En segon lloc, analitzem el pes quantitatiu global de les transferències sobre el conjunt de les dades.

${ }^{12}$ Cal dir que no ha estat fàcil delimitar aquest darrer fenomen en el nostre corpus. La gran similitud entre les dues llengües i l'absència d'un context on s'insereixen les unitats lèxiques ha fet que ens preguntéssim quan s'afegeix un significat a una forma lingüística existent o bé es transfereix una nova forma lingüística. És molt difícil establir els límits entre préstecs i calcs semàntics, com altres autors també dedicats al contacte castellà-català ja han assenyalat amb anterioritat (Hernández García, 1998, p. 218; Vila i Moreno, 1996, p. 50).

${ }^{13}$ Tot i això, cal dir que només 9 casos es troben en aquesta situació en el nostre corpus. Per raons d'espai, només incloem en aquest treball els préstecs que hem trobat. Per la resta de fenòmens, vg. Serrano Zapata (2014, pp. 504-537). En el fons d'aquesta limitació hi ha la doble perspectiva d'anàlisi dels fenòmens de contacte: com a processos en els quals es poden diferenciar diferents fases o com a resultats on es pot analitzar la relació entre les formes interferides i les estructures interferents. Hernández García (1998, pp. 175-177) explica i aborda la mateixa problemàtica en el seu treball. 


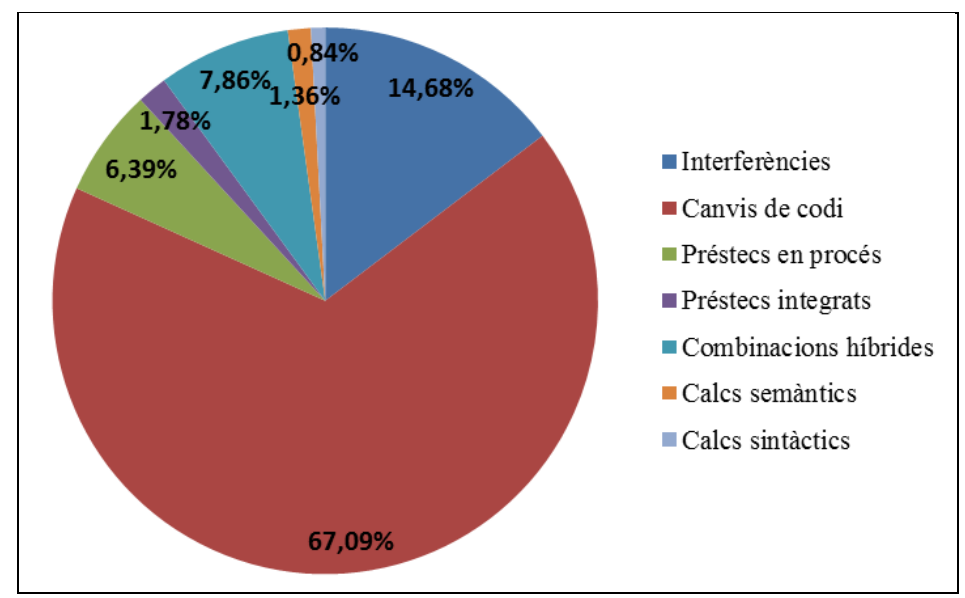

Gràfic 1. Distribució dels fenòmens de contacte lingüístic en el corpus

Taula 1. Pes quantitatiu global dels fenòmens de contacte lingüístic

\begin{tabular}{|l|c|}
\hline Total de paraules (respostes) & 76.061 \\
\hline Total de vocables (unitats lèxiques diferents) & 7.064 \\
\hline Transferències (valor absolut) & 945 \\
\hline Respostes amb algun element de contacte lingüístic & 4.141 \\
\hline Percentatge de transferències sobre el total de respostes & $5,44 \%$ \\
\hline Percentatge de transferències sobre el total del vocabulari & $13,38 \%$ \\
\hline Mitjana de respostes per informant amb alguna transferència & 17,25 \\
\hline
\end{tabular}

Tal com es pot veure a la taula 1 , les dades són diferents si considerem el pes que tenen els fenòmens de contacte lingüístic sobre el total de respostes aportades pels informants o si estudiem la seva importància en relació amb el conjunt del vocabulari català disponible. En el primer cas, utilitzem el total d'unitats lèxiques i observem que el pes percentual que tenen els elements del castellà sobre aquest paràmetre és del $5,44 \%$. Si observem aquesta mateixa dada per informant, ens trobem que cadascun produeix, aproximadament, 17,25 respostes que corresponen a transferències, cosa que ens dóna una mitjana d'1,01 per centre d'interès. D'altra banda, si considerem el valor que tenen els fenòmens de contacte sobre el conjunt del vocabulari català -considerant ara totes les transferències per igual amb independència del nombre de vegades que hagin estat esmentades- ens trobem que la influència és major, i concretament un 13,38\% del lèxic català està integrat per termes que són -en major o menor mesuraunitats lèxiques del castellà, una quantitat que ens sembla que cal tenir en consideració. 
Atès que la metodologia que empren tots els estudis de disponibilitat en l'actualitat és molt similar, podem comparar els nostres resultats amb els de Llopis (2009), que realitza un estudi sobre disponibilitat lèxica a les comarques catalanoparlants de València. El professor valencià troba que la mitjana del percentatge de transferències sobre el total de vocabulari és, en el seu cas, del $28,38 \%^{14}$, una xifra força superior al $13,38 \%$ que obtenim en el cas del català de Lleida. Sens dubte, la situació sociolingüística del català i el castellà a les dues províncies, València i Lleida, explica aquesta diferència en relació amb el volum que suposen els fenòmens de contacte lingüístic sobre el vocabulari. Encara que la mitjana de respostes que s'obté amb el mateix temps límit per centre d'interès és bastant similar a les dues comunitats (18,64 en el nostre cas i 18,30 en el seu), els estudiants de València semblen ignorar, en major mesura, quin és el lèxic català normatiu, almenys en les condicions artificials de l'enquesta de disponibilitat. Aquest fet provoca una substitució més àmplia del vocabulari del català pel de la llengua castellana.

Taula 2. Percentatge de fenòmens de contacte lingüístic sobre el total de vocables per centre d'interès

\begin{tabular}{|c|c|c|c|c|}
\hline núm. & Centre d'interès & $\begin{array}{c}\text { Total } \\
\text { de vocables }\end{array}$ & $\begin{array}{l}\text { Fenòmens } \\
\text { de contacte }\end{array}$ & $\%$ \\
\hline 1 & El cos humà & 364 & 33 & 9,07 \\
\hline 2 & Roba i complements & 313 & 65 & 20,77 \\
\hline 3 & Parts de la casa (sense els mobles) & 258 & 37 & 14,34 \\
\hline 4 & Mobles de la casa & 274 & 51 & 18,61 \\
\hline 5 & Aliments $i$ begudes & 523 & 74 & 14,15 \\
\hline 6 & Objectes col-locats a la taula per menjar & 282 & 61 & 21,63 \\
\hline 7 & La cuina i els seus utensilis & 373 & 63 & 16,89 \\
\hline 8 & L'escola: mobles i materials & 444 & 49 & 11,04 \\
\hline 9 & Il·luminació, calefacció i mitjans per airejar un recinte & 286 & 35 & 12,24 \\
\hline 10 & La ciutat & 658 & 51 & 7,75 \\
\hline 11 & El camp & 748 & 61 & 8,16 \\
\hline 12 & Mitjans de transport & 303 & 43 & 14,19 \\
\hline 13 & Treballs del camp i del jardi & 418 & 34 & 8,13 \\
\hline 14 & Animals & 434 & 111 & 25,58 \\
\hline 15 & Jocs i distraccions & 560 & 61 & 10,89 \\
\hline 16 & Professions i oficis & 577 & 71 & 12,31 \\
\hline 17 & Colors & 249 & 45 & 18,07 \\
\hline
\end{tabular}

${ }^{14}$ Hem calculat la mitjana a partir de les dades que dóna l'autor de cadascun dels centres d'interès (Llopis, 2009, pp. 321-323). 
Si ens fixem ara en el percentatge de transferències sobre el vocabulari de cada centre d'interès que es reflecteix a la taula 2 , veiem que es produeixen diferències destacables entre cadascun dels àmbits que es proposen a l'enquesta. Mentre que en alguns centres els informants produeixen una gran quantitat de transferències (com succeeix a Animals, Objectes col-locats a la taula per menjar o Roba i complements), altres queden clarament per sota de la mitjana amb un percentatge molt baix d'elements transferits (per exemple, Treballs del camp i del jardí, El camp ${ }^{15}$ o El cos humà).

Creiem que aquestes diferències es poden explicar perquè algunes de les àrees que ocupen les primeres posicions a la classificació (com Objectes col-locats a la taula per menjar, Roba i complements, Mobles de la casa o La cuina $i$ els seus utensilis) estan estretament relacionades amb l'àmbit familiar i, per tant, amb la llengua inicial de l'informant. Cal recordar en aquest punt que, del total de 240 informants que omplen l'enquesta, n'hi ha 66 la primera llengua dels quals és el castellà. Podríem pensar que aquests informants tendeixen a esmentar paraules en la seva pròpia llengua materna al voltant d'aquests àmbits de caire eminentment domèstic i també en alguns altres (com Animals, Colors o Mitjans de transport) on la presència de lèxic adquirit durant l'infantesa és important (com demostra Hernández Muñoz, 2006) ${ }^{16}$.

Tanmateix, si tenim en compte que tots els nostres informants han estat escolaritzats íntegrament en català, que a l'escola es treballa específicament el lèxic d'alguns d'aquests àmbits (com Animals o Mitjans de transport) i que el pes dels castellanoparlants $^{17}$ a la mostra és clarament minoritari (el 27,50\%), sembla difícil atribuir a aquest col-lectiu la responsabilitat de tota la producció de transferències trobada. Més aviat ens inclinem a pensar que, en aquests resultats, s'aprecia el predomini social que ha tingut el castellà sobre la llengua històrica de la comunitat, afavorit per les circumstàncies sociopolítiques del segle $\mathrm{XX}^{18}$. Per la informació que tenim fins ara, tot fa pensar que els alumnes catalanopar-

\footnotetext{
${ }^{15}$ No sembla casualitat que en aquests dos àmbits el percentatge de fenòmens de contacte lingüístic sigui baix, donada la relació que hi ha entre l'ús de la llengua històrica i territorial i el medi rural. Respecte a El cos humà, Bartol (2011, pp. 160-162) ja adverteix que aquest centre no propicia la transferència d'altres llengües.

${ }^{16}$ És impossible corroborar aquesta hipòtesi fins que no analitzem les dades segons la llengua materna de l'informant.

${ }^{17}$ Utilitzem aquest terme per referir-nos als informants la llengua materna dels quals és el castellà i el de catalanoparlants per referir-nos als que tenen el català com a llengua inicial. Tots els informants que han participat en aquest estudi són bilingües i dominen el castellà i el català.

${ }^{18}$ Principalment, un llarg període de subordinació política i l'arribada massiva d'immigrants monolingües a un entorn on els parlants o ja eren bilingües o van acabar sent-ho (Boix, 2004). A més, els hàbits lingüístics de la població s'han caracteritzat durant molts anys per una convergència cap al castellà, malgrat que la situació està canviant en l'actualitat (Pujolar, González, Font \& Martínez, 2010).
} 
lants ja aprenen transferències en la seva llengua materna, és a dir, que la llengua catalana conté un percentatge gens menyspreable de vocables del castellà que es transmeten de generació en generació, segurament com a resultat del fet que les generacions anteriors no van ser instruïdes en català.

\section{ESTUDI DELS PRÉSTECS}

És evident la utilitat de conèixer quines unitats concretes estan sent substituïdes, o corren aquest risc, per altres en una comunitat lingüística, ja que d'aquesta forma, amb una planificació lingüística adequada a l'escola, es pot treballar per tal d'evitar els casos de substitució lèxica més freqüents.

Com ja hem dit a la introducció, una de les possibilitats més interessants que tenim amb les enquestes de disponibilitat és comprovar el desplaçament dels equivalents sinònims, una possibilitat que ja va utilitzar Mackey $(1971,1976)$ en el seu estudi pioner sobre el lèxic disponible francès al Canadà. A més, també és possible comparar dos índexs matemàtics que tenen un interès especial: el percentatge d'aparició (és a dir, la proporció d'informants que actualitza un mot) i l'índex de disponibilitat (que combina la freqüència d'una unitat amb la posició que ha obtingut a cada llistat). A les dues taules que presentem seguidament (taula 3: Prèstecs en procés d'integració; taula 4: Prèstecs integrats), es pot observar en primera posició el centre d'interès en què apareix el préstec $i$ el sinònim equivalent en català $(\mathrm{CI})$, la posició que obté la unitat al diccionari final $(\mathrm{P})$, el percentatge d'aparició (A) i l'índex de disponibilitat (ID).

Taula 3. Préstecs en procés d'integració

\begin{tabular}{|c|c|c|c|c|c|c|c|c|}
\hline $\mathrm{CI}$ & Préstec & $\mathrm{P}$ & $\mathrm{A}(\%)$ & ID & Equivalent & $P$ & $\mathrm{~A}(\%)$ & ID \\
\hline 1 & muñeca & 71 & 7,500 & 0,02974 & canell & 35 & 25,000 & 0,10994 \\
\hline 2 & blusa & 49 & 10,833 & 0,05947 & brusa & 55 & 6,667 & 0,04250 \\
\hline 2 & chaleco & 56 & 9,167 & 0,03724 & armilla & 53 & 10,417 & 0,04375 \\
\hline 2 & chándal & 57 & 8,333 & 0,03622 & xandall & 34 & 23,333 & 0,10724 \\
\hline 2 & pajarita & 73 & 6,667 & 0,02709 & corbatit $^{19}$ & 161 & 0,833 & 0,00535 \\
\hline 2 & sostén & 66 & 5,833 & 0,02969 & sostenidor & 39 & 17,500 & 0,09170 \\
\hline 2 & sudadera & 50 & 10,833 & 0,05700 & dessuadora & - & & \\
\hline 2 & traje & 71 & 6,667 & 0,02827 & vestit $^{20}$ & 25 & 29,167 & 0,15688 \\
\hline
\end{tabular}

${ }^{19}$ L'expressió sinònima corbata de llacet no apareix.

${ }^{20}$ Més que a un vestit, intuïm que els informants, quan inclouen aquesta transferència del castellà, es refereixen al conjunt de pantaló, jaqueta i armilla, que en català normatiu seria tern, que cap informant inclou. 
Taula 3

\begin{tabular}{|c|c|c|c|c|c|c|c|c|}
\hline CI & Préstec & $\mathrm{P}$ & $\mathrm{A}(\%)$ & ID & Equivalent & $\mathrm{P}$ & $\mathrm{A}(\%)$ & ID \\
\hline 3 & bodega & 36 & 10,000 & 0,04004 & $\begin{array}{l}\text { rebost } \\
\text { celler }\end{array}$ & $\begin{array}{l}15 \\
43\end{array}$ & $\begin{array}{r}36,250 \\
5,417\end{array}$ & $\begin{array}{l}0,18702 \\
0,02676\end{array}$ \\
\hline 3 & buhardilla & 45 & 5,417 & 0,02648 & (es)golfa & 16 & 37,500 & 0,17972 \\
\hline 3 & despensa & 25 & 10,833 & 0,05370 & rebost & 15 & 36,250 & 0,18702 \\
\hline 3 & recibidor & 40 & 5,000 & 0,03321 & rebedor & 4 & 65,833 & 0,45803 \\
\hline 4 & armari empotrat* & 38 & 6,667 & 0,03307 & armari encastat & - & & \\
\hline 4 & lámpara & 22 & 11,667 & 0,06239 & $\begin{array}{l}\text { làmpada } \\
\text { llum }\end{array}$ & $\begin{array}{r}69 \\
109\end{array}$ & $\begin{array}{l}2,500 \\
1,667\end{array}$ & $\begin{array}{l}0,01436 \\
0,00669\end{array}$ \\
\hline 4 & mesita & 26 & 7,917 & 0,04961 & tauleta & 10 & 21,667 & 0,14213 \\
\hline 4 & silló* & 36 & 5,417 & 0,03398 & butaca $^{21}$ & 6 & 52,500 & 0,31209 \\
\hline 5 & gaseosa & 40 & 14,167 & 0,08821 & gasosa & 132 & 3,750 & 0,02130 \\
\hline 5 & mermelada & 158 & 5,000 & 0,01527 & melmelada & 503 & 0,417 & 0,00125 \\
\hline 5 & ron & 94 & 7,500 & 0,03853 & rom & 265 & 0,833 & 0,00590 \\
\hline 6 & mantell* & 26 & 11,667 & 0,06637 & (es)tovalles & 7 & 47,917 & 0,29394 \\
\hline 6 & servilleta & 37 & 5,833 & 0,03986 & tovalló & 5 & 77,917 & 0,49780 \\
\hline 7 & batidora & 27 & 14,583 & 0,07752 & batedora & 40 & 10,000 & 0,04982 \\
\hline 7 & cucharón & 56 & 5,833 & 0,02914 & cullerot & 13 & 23,333 & 0,16663 \\
\hline 7 & exprimidora & 41 & 10,833 & 0,04881 & espremedora & 221 & 1,250 & 0,00327 \\
\hline 7 & sandwichera & 48 & 8,750 & 0,03731 & sandvitxera & 122 & 2,500 & 0,00884 \\
\hline 7 & sartén & 33 & 9,167 & 0,06294 & paella & 1 & 65,833 & 0,46439 \\
\hline 8 & carpessà* & 57 & 10,000 & 0,03669 & carpeta d'anelles & - & & \\
\hline 8 & carpesano & 85 & 5,833 & 0,01870 & carpeta d'anelles & - & & \\
\hline 8 & esquadra & 63 & 7,500 & 0,03324 & escaire & 53 & 8,750 & 0,04343 \\
\hline 8 & mochila & 59 & 8,750 & 0,03563 & motxilla & 23 & 23,750 & 0,10621 \\
\hline 8 & ordenador & 40 & 12,083 & 0,06356 & ordinador & 25 & 23,333 & 0,09865 \\
\hline 8 & pegament* & 74 & 6,250 & 0,02528 & pega $^{22}$ & 115 & 2,500 & 0,01014 \\
\hline 8 & tissa* & 61 & 7,083 & 0,03458 & guix & 9 & 56,667 & 0,32722 \\
\hline 8 & papelera & 65 & 7,917 & 0,03199 & paperera & 29 & 20,000 & 0,08904 \\
\hline 8 & taquilla & 54 & 8,333 & 0,04107 & caseller, armariet & $\begin{array}{l}192 \\
331 \\
\end{array}$ & $\begin{array}{l}0,833 \\
0,417 \\
\end{array}$ & $\begin{array}{l}0,00425 \\
0,00173 \\
\end{array}$ \\
\hline 9 & bombilla & 17 & 12,083 & 0,08489 & bombeta & 3 & 61,667 & 0,45370 \\
\hline 9 & calentador & 31 & 5,000 & 0,03192 & escalfador & 71 & 1,250 & 0,00965 \\
\hline 9 & vela & 32 & 6,250 & 0,03152 & espelma & 18 & 15,417 & 0,07945 \\
\hline 10 & acera & 52 & 7,500 & 0,05420 & vorera & 36 & 14,167 & 0,07914 \\
\hline 10 & pas de peatons* & 60 & 6,667 & 0,04103 & pas de vianants & 90 & 3,333 & 0,02307 \\
\hline 10 & peató* & 63 & 6,667 & 0,04016 & vianant & 65 & 7,500 & 0,03862 \\
\hline 12 & barco & 32 & 7,083 & 0,04183 & vaixell & 7 & 77,500 & 0,44355 \\
\hline
\end{tabular}

${ }^{21}$ Un altre vocable sinònim, cadira de braços, no apareix.

${ }^{22}$ Cap informant menciona l'altra expressió equivalent (goma d'enganxar). 
Taula 3

\begin{tabular}{|r|l|r|r|r|l|r|r|c|}
\hline CI & \multicolumn{1}{|c|}{ Préstec } & \multicolumn{1}{c|}{$\mathrm{P}$} & \multicolumn{1}{c|}{$\mathrm{A}(\%)$} & \multicolumn{1}{c|}{ ID } & \multicolumn{1}{c|}{ Equivalent } & \multicolumn{1}{c|}{$\mathrm{P}$} & A $(\%)$ & ID \\
\hline 12 & lancha & 40 & 7,083 & 0,02625 & llanxa & 52 & 4,167 & 0,01851 \\
\hline 12 & patera & 48 & 5,417 & 0,02300 & pastera & - & & \\
\hline 13 & abonar & 16 & 14,583 & 0,09032 & adobar (la terra) & 18 & 14,167 & 0,08837 \\
\hline 13 & cosechar & 26 & 7,500 & 0,04663 & collir recol·lectar & 6 & $\begin{array}{r}37,500 \\
8,750\end{array}$ & $\begin{array}{r}0,24293 \\
0,04952\end{array}$ \\
\hline 14 & ballena & 64 & 12,083 & 0,05193 & balena & 26 & 33,333 & 0,13752 \\
\hline 14 & delfí* & 91 & 6,667 & 0,02710 & dofí & 22 & 34,583 & 0,15820 \\
\hline 14 & jabalí & 87 & 5,833 & 0,02877 & porc senglar & 5 & 15,000 & 0,06330 \\
& & & & & porc fer & 223 & 0,833 & 0,00508 \\
\hline 14 & tiburó* & 72 & 9,167 & 0,04184 & tauró & 28 & 34,583 & 0,13645 \\
\hline 14 & tocino & 94 & 5,000 & 0,02581 & porc & 8 & 50,833 & 0,29296 \\
\hline 15 & escondite & 28 & 13,333 & 0,07361 & amagatall & 94 & 2,917 & 0,01798 \\
\hline 15 & ordenador & 33 & 8,750 & 0,05546 & ordinador & 11 & 23,333 & 0,14173 \\
\hline 15 & teto & 44 & 5,000 & 0,04227 & - & & & \\
\hline 15 & uno & 51 & 5,417 & 0,03493 & - & & & \\
\hline 16 & abogat* & 47 & 10,833 & 0,05756 & advocat & 9 & 29,167 & 0,18403 \\
\hline 16 & camarer* & 75 & 5,833 & 0,03735 & cambrer & 15 & 26,250 & 0,14843 \\
\hline 16 & enfermer* & 48 & 9,583 & 0,05744 & infermer & 14 & 26,667 & 0,14858 \\
\hline 16 & ingenier* & 84 & 5,833 & 0,03119 & enginyer & 29 & 17,500 & 0,09723 \\
\hline 16 & peluquer* & 81 & 6,250 & 0,03230 & perruquer & 40 & 12,500 & 0,07393 \\
\hline 17 & marrón & 44 & 5,000 & 0,02877 & marró & 11 & 82,083 & 0,44776 \\
\hline
\end{tabular}

Taula 4. Préstecs integrats

\begin{tabular}{|r|l|r|r|r|l|r|r|c|}
\hline CI & \multicolumn{1}{|c|}{ Préstec } & P & A (\%) & \multicolumn{1}{c|}{ ID } & Equivalent & P & A (\%) & ID \\
\hline 1 & hombro & 43 & 18,750 & 0,08407 & espatlla & 34 & 27,083 & 0,11523 \\
\hline 2 & bolso & 21 & 32,083 & 0,17374 & bossa de mà $^{23}$ & 175 & 0,833 & 0,00417 \\
\hline 2 & (forro) (polar) & 44 & 17,500 & 0,07831 & folre polar & - & & \\
\hline 2 & gorro & 35 & 23,333 & 0,10473 & gorra $^{24}$ & 24 & 32,917 & 0,16132 \\
\hline 2 & sostens* & 29 & 28,333 & 0,13631 & sostenidor & 39 & 17,500 & 0,09170 \\
\hline 6 & mantel & 13 & 18,750 & 0,11543 & (es)tovalles & 7 & 47,917 & 0,29394 \\
\hline 8 & borrador & 17 & 31,667 & 0,15949 & esborrador & 44 & 10,833 & 0,05734 \\
\hline 9 & $\begin{array}{l}\text { (aparell d')aire } \\
\text { acondicionat* }\end{array}$ & 5 & 57,917 & 0,40986 & $\begin{array}{l}\text { (aparell d')aire } \\
\text { condicionat }\end{array}$ & 11 & 17,917 & 0,13007 \\
\hline 9 & foco & 15 & 18,750 & 0,11067 & focus & - & & \\
\hline
\end{tabular}

${ }^{23}$ L'equivalent exacte és aquest, rarament usat tal com es veu. La paraula bossa sense especificació apareix a la posició 54, també per sota de bolso, malgrat que pot referir-se a altres referents, molt allunyats de bolso.

${ }^{24}$ Altres sinònims com casquet, capell o capçó no surten a cap enquesta. 
Taula 4

\begin{tabular}{|r|l|r|r|c|l|r|r|c|}
\hline CI & \multicolumn{1}{|c|}{ Préstec } & $\mathrm{P}$ & $\mathrm{A}(\%)$ & $\mathrm{ID}$ & Equivalent & $\mathrm{P}$ & $\mathrm{A}(\%)$ & $\mathrm{ID}$ \\
\hline 9 & lámpara & 8 & 40,833 & 0,27161 & llum, làmpada & $\begin{array}{r}13 \\
23\end{array}$ & $\begin{array}{r}15,833 \\
8,750\end{array}$ & $\begin{array}{r}0,11672 \\
0,05869\end{array}$ \\
\hline 10 & farola & 23 & 18,333 & 0,11640 & fanal & 117 & 2,500 & 0,01464 \\
\hline 14 & mono & 15 & 33,750 & 0,16687 & mona, simi, mico & $\begin{array}{r}122 \\
171\end{array}$ & $\begin{array}{r}2,500 \\
1,667\end{array}$ & $\begin{array}{c}0,01654 \\
0,00822 \\
\end{array}$ \\
& & & & & 53 & 13,333 & 0,06306 \\
\hline 15 & pilla pilla & 17 & 17,500 & 0,11002 & tocar i parar & 80 & 3,750 & 0,02192 \\
\hline 15 & (video)consola & 21 & 15,833 & 0,09422 & consola de joc & - & & \\
\hline 16 & fontaner & 31 & 17,083 & 0,09438 & llauner, lampista & $\begin{array}{r}123 \\
97\end{array}$ & 3,333 & 0,01865 \\
& & & & & & 41 & 10,000 & 0,02443 \\
\hline 17 & dorat* & 23 & 27,917 & 0,11578 & daurat & 0,04415 \\
\hline 17 & granate & 17 & 37,500 & 0,18105 & granat & 129 & 0,833 & 0,00317 \\
\hline
\end{tabular}

Es recullen en total 76 préstecs diferents, dels quals $36^{25}$ desplacen el sinònim corresponent català i tenen un valor major de disponibilitat i d'aparició. Això significa que gairebé la meitat dels préstecs recollits, un 47,37\%, reemplacen el correlat català. Si ens fixem en la distribució dels préstecs en funció de la seva integració, veurem que un 38,33\% (23 de 60) dels préstecs en procés d'integració substitueixen el vocable propi del català; aquest fet es dóna en el $82,35 \%$ dels préstecs ja integrats (14 de 17).

D'altra banda, els préstecs recollits són principalment vocables normatius castellans (52 exemples, el 68,42\%). És menor la presència de calcs semàntics (6 casos, el 7,89\%) i més minsa encara la presència de combinacions híbrides $(3 \text { exemples, el 3,95\% })^{26}$. Els préstecs agramaticals, basats en una interferència que s'ha difós, tenen, per contra, un pes més alt $\left(15\right.$, el $\left.19,74 \%{ }^{27}\right)$. Així mateix, considerem bastant significatiu que en 9 dels 36 préstecs que desplacen al lèxic propi del català -és a dir, en el $25 \%$ dels casos- el terme propi de la llengua catalana ni tan sols aparegui en els llistats, com succeeix amb dessuadora, armari encastat, carpeta d'anelles, focus, consola de joc, folre polar... ${ }^{28}$

${ }^{25}$ En realitat, si sumem la informació de les taules 3 i 4, la quantitat exacta és 78, i la de préstecs que superen el seu sinònim, 37. Les xifres que apareixen al text són el resultat de restar a aquestes dades els préstecs repetits, lámpara i ordenador, que apareixen en més d'un centre d'interès.

${ }^{26}$ Alguns exemples de calcs semàntics, reconeixent les dificultats que hem tingut a l'hora d'establir-los (vg. la nota 12), són bodega 'celler, rebost', taquilla 'armariet, caseller' o fontaner 'llauner, lampista'. Els tres casos de combinacions híbrides són armari empotrat", (aparell d')aire acondicionat* i pas de peatons*.

${ }^{27}$ Aquests casos es troben marcats amb un asterisc a les taules 3 i 4 . També es marquen d'aquesta manera les combinacions sintagmàtiques amb algun element híbrid.

${ }^{28}$ En els casos teto i uno l'equivalent en català no apareix perquè es tracta d'expressions més extenses fetes totalment en castellà o de jocs que no tenen un equivalent en la llengua catalana. 


\section{CONCLUSIONS}

La hipòtesi de la qual hem partit, que esperàvem trobar un nombre elevat de fenòmens de contacte lingüístic al lèxic disponible català -donat el context plurilingüe en què ens trobem a Lleida, on hi ha tota una gamma de contactes lingüístics majoritàriament asimètrics, amb intensitats diferents en funció de la llengua inicial- ha estat àmpliament corroborada. Al llarg d'aquest treball hem classificat totes les transferències que hem trobat en el nostre corpus i n'hem analitzat el valor sobre les dades, en global i per centres d'interès. De totes les dades que hem obtingut, creiem que la més remarcable és que el 13,38\% del lèxic disponible català està integrat per elements de la llengua castellana. A més, en l'anàlisi concreta dels préstecs observem com gairebé la meitat de les vegades (el 47,37\%), els préstecs obtenen índexs superiors de freqüència i disponibilitat respecte als sinònims equivalents catalans. Amb aquestes dades sobre la taula, no podem sinó concloure que, malgrat els esforços realitzats per les diferents institucions per normalitzar la llengua catalana, i encara que el català és una llengua de prestigi en l'actualitat a Catalunya, el pes dels més de quaranta anys en què el seu ús va ser relegat a l'àmbit familiar durant el segle passat es segueix evidenciant en la llengua, tal com ho demostra la proporció significativa de transferències del castellà que són presents en el lèxic disponible català. 


\section{BIBLIOGRAFIA}

Bartol, J. A. (2011). Léxicos disponibles de zonas bilingües: interferencias sobre el español. Dins B. López Meirama (Ed.), Estudios sobre disponibilidad léxica en el español de Galicia (pp. 157-188). Santiago de Compostela: Universidade de Santiago de Compostela.

Boix, E. (2004). El camí fins a la situació contemporània del català i del castellà a Catalunya: entre la complexitat i la fragilitat. Dins Ll. Payrató \& F. X. Vila (Dirs.), Les llengües a Catalunya (pp. 13-27). Sabadell: Fundació Caixa de Sabadell (Cicle Joan Coromines, III).

Gimeno Menéndez, F. \& Gimeno Menéndez, Mª V. (2003). El desplazamiento lingüístico del español por el inglés. Madrid: Cátedra.

Gómez Devís, B. (1995). Estudi descriptiu sobre disponibilitat lèxica del valencià en la ciutat de València i àrea metropolitana. Pla Eva (treball inèdit).

Hernández García, C. (1998). Algunas cuestiones más sobre el contacto de lenguas: Estudio de la interferencia lingüistica del catalán en el español de Cataluña (tesi doctoral inèdita). Barcelona: Universitat de Barcelona.

Hernández Muñoz, N. (2006). Hacia una teoría integrada de la disponibilidad léxica: el léxico disponible de los estudiantes castellano-manchegos. Salamanca: Ediciones de la Universidad de Salamanca.

Llopis Rodrigo, F. (2009). El lèxic del valencià central: un estudi de disponibilitat lèxica. València: Servei de Publicacions de la Universitat de València.

Mackey, W. F. (1971). Le vocabulaire disponible du français. Paris, Bruxelles \& Montréal: Didier.

- (1976). Bilinguisme et contact des langues. Paris: Klincksieck.

Massana, J. Ma. (2004). Diccionari de lleidatanismes. Lleida: Pagès editors.

Masip, R., Montardit, F. \& Prenafeta, D. (2010). Lo nou diccionari català-lleidatà. Lleida: Alfazeta.

Pujolar, J., González, I., Font A. \& Martínez, R. (2010). Llengua i joves. Usos i percepcions lingüistics de la joventut catalana. Barcelona: Generalitat de Catalunya, Departament d'Acció Social i Ciutadania.

Serrano Zapata, M. (2014). Disponibilidad léxica en la provincia de Lleida: estudio comparado de dos lenguas en contacto (tesi doctoral). Lleida: Universitat de Lleida. Obtingut de http://hdl.handle.net/10803/285008

Vila i Moreno, F. X. (1996). When classes are over. Language choice and Language contact in bilingual education in Catalonia. Proefschrift aangeboden tot het behalen van de graad van Doctor in de Taal-en Letterkunde (tesi doctoral). Faculteit der Letteren en Wijsbegeerte, Vrije Universiteit Brussel. 